\title{
Solitary Deaths in the Tokyo Metropolis and Labor Force Status: Characteristics of Unnatural Deaths at Home among Persons Living Alone
}

\author{
Yoshimasa Kanawaku ${ }^{1,2}$ and Youkichi Ohno ${ }^{1}$ \\ ${ }^{1}$ Department of Legal Medicine, Nippon Medical School, Tokyo, Japan \\ ${ }^{2}$ Tokyo Medical Examiner's Office, Tokyo Metropolitan Government, Tokyo, Japan
}

\begin{abstract}
Objective: To identify associations of solitary death with social determinants of health, namely, labor force status and welfare status, in Tokyo in 2015.

Methods: We obtained data on solitary deaths in 2015 in the 23 special wards of Tokyo and calculated the incidence rate and postmortem interval of solitary death in relation to sex, age, and labor force status.

Results: Data for 3,972 solitary deaths (2,785 males, 1,187 females) were analyzed. The non-employed rate was $79.3 \%$ among males and $89.5 \%$ among females. The incidence rate was significantly higher among non-employed persons than among employed persons in both sexes. Moreover, with the exception of women 65 years or older, the postmortem interval was significantly longer among nonemployed persons than among employed persons in both sexes.

Conclusions: The incidence rates of solitary death were significantly higher among non-employed persons than among employed persons in both sexes, and the postmortem interval was significantly longer for non-employed persons. (J Nippon Med Sch 2019; 86: 360-363)
\end{abstract}

Key words: solitary death, unnatural death, medical examiner, labor force status

\section{Introduction}

Because single-person households are common and increasing in Japan ${ }^{1}$, deaths at home of persons living alone, sometimes referred to as "solitary deaths," are of considerable interest ${ }^{2}$. The number of solitary deaths is expected to continue to increase; therefore, multiple government initiatives have been developed to address this social problem ${ }^{3}$. Although numerous studies have investigated the demographics of solitary deaths ${ }^{4,5}$, few have investigated the relationship between solitary death and social determinants of health, that is, the conditions in places where people live, learn, work, and play, which affect a wide range of health risks and outcomes ${ }^{6}$.

To augment basic social epidemiological data on solitary death, we investigated the characteristics of solitary deaths in Tokyo wards in 2015 in relation to social determinants of health, namely, labor force status and welfare status.

\section{Methods}

Solitary death was defined as an unnatural death at the home of a person living alone in a private household. Solitary deaths are by definition not witnessed and are therefore classified as unnatural. The Tokyo Medical Examiner's Office (TMEO) is responsible for investigating all unnatural deaths that occur in the 23 wards of Tokyo and therefore must investigate all solitary deaths in that jurisdiction. We used the TMEO database of unnatural deaths to investigate solitary deaths in the special wards of the Tokyo metropolis. Using prespecified exclusion criteria (see Fig. 1A), we selected the decedents included in the analyses.

Because few solitary deaths were classified as suicide, accidental death, or criminal death, those cases were excluded. Thus, the present decedents comprised deaths due to disease, mainly sudden cardiac death. The number and incidence rate (number of cases per 1,000 single-

Correspondence to Yoshimasa Kanawaku, Department of Legal Medicine, Nippon Medical School, 1-1-5 Sendagi, Bunkyo-ku, Tokyo 113-8602, Japan

E-mail: ykanawaku@nms.ac.jp

https://doi.org/10.1272/jnms.JNMS.2019_86-604

Journal Website (https://www.nms.ac.jp/sh/jnms/) 


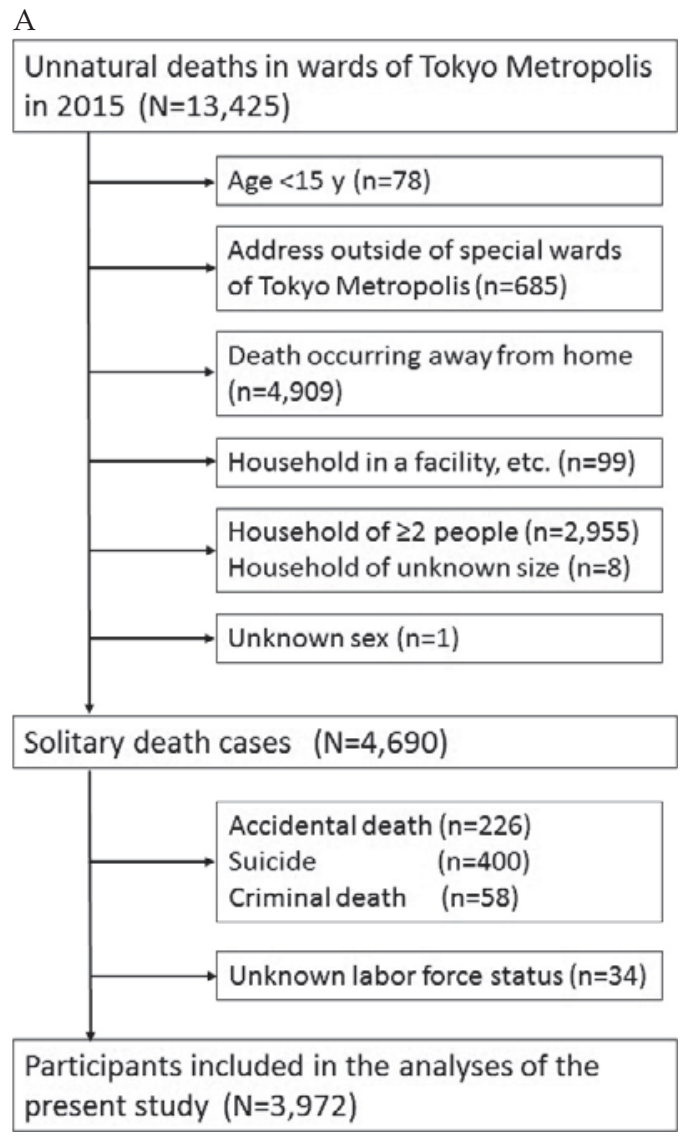

A. Flow diagram of case selection.

B. Incidences of solitary death, by sex, age, and labor force status

(a) men, (b) women. The $x$ - and y-axes represent age and incidence of solitary deaths, respectively. The Pearson chi-square test was used for comparisons. The Fisher exact test was used to analyze the small number of decedents aged 15-34 years. * : p<0.01. person households) of solitary deaths, postmortem interval (number of days from death to postmortem examination), and percentage of welfare recipients were analyzed in relation to sex, age, and labor force status (employed or non-employed). The postmortem interval was recorded as 0.5 when death and postmortem examination occurred on the same day. To calculate incidence rate, demographic data were obtained from the 2015 Population Census? ${ }^{7}$. When appropriate, the Pearson chi-square and Wilcoxon rank-sum tests were used for comparisons. A $P$ value of less than 0.05 was considered to indicate statistical significance. All statistical analyses were performed by using MATLAB R2014b (MathWorks, Inc., Natick, MA, USA).

This study was approved by the ethics committee of the TMEO. The requirement for individual informed consent was waived by the national research ethics guidelines of Japan.

\section{Results and Discussion}

Table 1 shows the numbers of solitary deaths, by sex, age, and labor force status.

Among solitary deaths, 2,785 were male and 1,187 were female. The non-employed rate was $79.3 \%(2,209 /$ $2,785)$ among males and $89.5 \%(1,062 / 1,187)$ among females. Incidences by sex, age, and labor force status are shown in Figure 1B.

With the exception of males aged 15-24 years and 2534 years and women 85 years or older, incidence was significantly higher among non-employed persons than among employed persons in both sexes.

Figure 2A shows box plots of postmortem intervals, by sex, age, and labor force status.

With the exception of women 65 years or older, the postmortem interval was significantly longer for nonemployed persons than for employed persons in both sexes. In addition, the median postmortem interval was 1 to 5 days longer for non-employed persons than for employed persons. 
Table 1 Numbers of solitary deaths, by sex, age, and labor force status

\begin{tabular}{|c|c|c|c|c|}
\hline \multirow[b]{2}{*}{ Age } & \multicolumn{2}{|c|}{ Males } & \multicolumn{2}{|c|}{ Females } \\
\hline & Non-employed & Employed & Non-employed & Employed \\
\hline $15-24 \mathrm{y}$ & 2 & 2 & 1 & 0 \\
\hline $25-34 y$ & 9 & 17 & 1 & 4 \\
\hline $35-44 \mathrm{y}$ & 55 & 58 & 5 & 7 \\
\hline $45-54 \mathrm{y}$ & 144 & 106 & 43 & 13 \\
\hline $55-64 \mathrm{y}$ & 401 & 179 & 65 & 24 \\
\hline $65-74 \mathrm{y}$ & 834 & 159 & 182 & 24 \\
\hline $75-84 \mathrm{y}$ & 579 & 42 & 443 & 39 \\
\hline$\geq 85 y$ & 185 & 13 & 322 & 14 \\
\hline Total & 2,209 & 576 & 1,062 & 125 \\
\hline
\end{tabular}

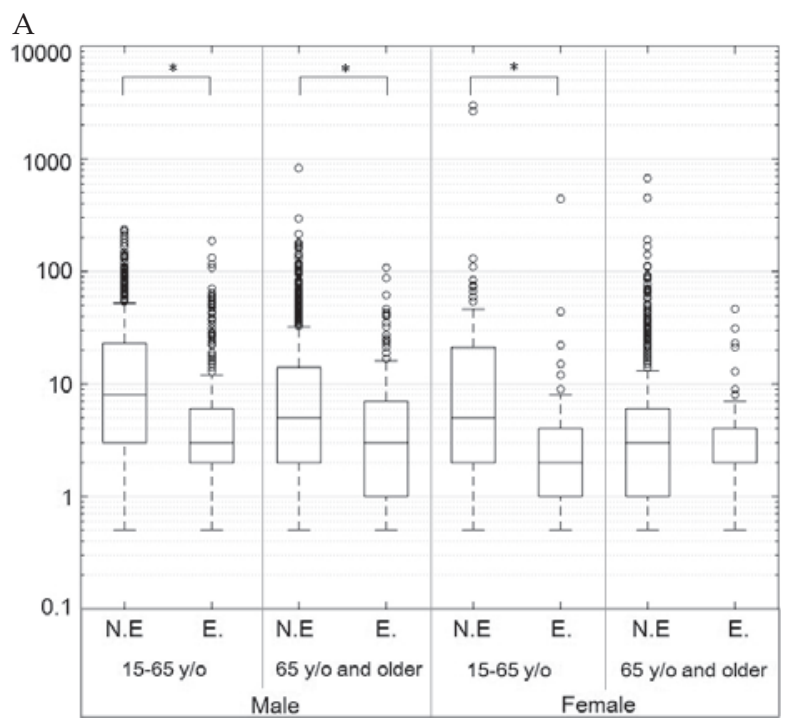

B

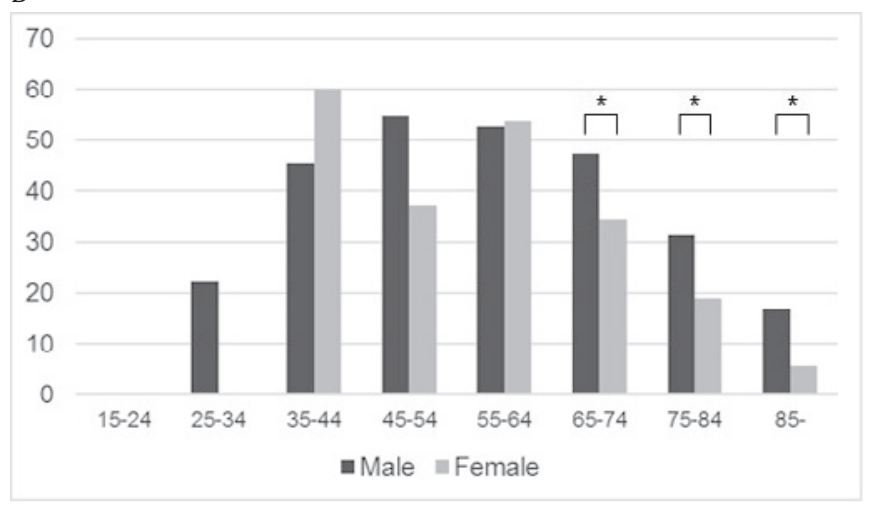

A. Postmortem interval, by sex, age, and labor force status

Fig. 2

The y-axis represents the postmortem interval on a logarithmic scale. The lines at the top, middle, and bottom of each box represent the 25th percentile, median, and 75th percentile of the samples, respectively. An outlier (shown as a circle) was defined as a data point located outside the "whiskers" of the boxplot; these values are more than 1.5 times the interquartile range away from the top or bottom of the box. The Wilcoxon rank-sum test was used for comparisons. N.E.: non-employed; E: employed. *: $\mathrm{p}<0.01$.

B. Percentages of welfare recipients among solitary deaths in non-employed persons, by sex and age

(a) men, (b) women. The $x$ - and $y$-axes represent age and the percentage of welfare recipients among solitary deaths, respectively. The Pearson chi-square test was used for comparisons. The Fisher exact test was used to analyze the small number of decedents aged 15-34 years. *: $\mathrm{p}<0.01$.

Figure 2B shows the percentages of welfare recipients among solitary deaths in non-employed persons, in relation to sex and age.

In males and females, about half of persons aged 35-64 years were welfare recipients. The percentage of welfare recipients decreased with age among males and females. Additionally, statistical significance of the differences of percentage of men to women was observed in those adults 65 years or older.

The incidence rates of solitary death were significantly higher among non-employed persons than among em- ployed persons in both sexes (with the exception of the youngest decedents and women 85 years or older) and the median postmortem interval was significantly longer, with the exception of women 65 years or older. In particular, the high rate of solitary death among nonemployed persons and persons younger than 65 years is noteworthy. The reason for the difference in the rates for employed and non-employed persons is unclear; however, our results suggest that further investigation of the labor force status of solitary death cases is warranted.

The postmortem interval differed in relation to labor 
force status. Among non-employed persons, the median postmortem interval was 3-8 days, but some deaths were discovered after longer than 100 days. Such cases suggest an extreme lack of social interaction. Another interesting finding was that the rate of welfare receipt was significantly lower among women older than 65 years. A previous study reported that self-rated health was low among welfare recipients ${ }^{8}$ and that long-term welfare recipients were less likely to participate in health evaluations? These findings might help explain the solitary death rate among welfare recipients.

In conclusion, we observed an association between solitary death and labor force status. To identify any cause-effect relationship between solitary death and labor force status, future research should investigate the high rate of solitary death and long postmortem interval among non-employed persons. We believe that the results of such studies could have implications for measures to prevent solitary death, especially among nonemployed, middle-aged adults living alone.

Conflict of Interest: The authors report no conflicts of interest.

\section{References}

1. Statistics Bureau, Ministry of Internal Affairs and Communications. Population and Households of Japan. Tokyo, JPN: 2010. pp. 70-77. http://www.stat.go.jp/englis h/data/kokusei/2010/poj/pdf/2010ch09.pdf. Accessed
Dec 42018.

2. Kotsuji H, Kobayashi M: History of news reports on lonely death. Core ethics 2011; 7: 121-130.

3. Ministry of Health, Labour and Welfare. The Policies and Actions for Prevention of Solitary Deaths. Tokyo; 2013. ht tp://www.mhlw.go.jp/stf/seisakunitsuite/bunya/000003 4189.html. Accessed Dec 42018.

4. Kanawaku Y, Mori S, Abe N, Tanifuji T, Shigeta A, Fukunaga T, Funayama M, Kanetake J, Suzuki K: Unexpected death statistics according to classification of households: survey of solitary-death statistics in the Tokyo metropolitan area. J Health Welf Stat 2010; 57: 20-25.

5. Matsuzawa A, Tamiya N, Yamamoto $H$, Yamamoto $H$, Yamazaki K, Motozawa M, Miyaishi S: The realities and background factors of senior citizen deaths in autopsy cases of so-called solitary-deaths. J Health Wel Stat 2009; 56: $1-7$.

6. The U.S. Department of Health and Human Services. Healthy People 2020: Social Determinants of Health. http s:/ / www.healthypeople.gov/2020/topics-objectives/topi c/social-determinants-of-health. Accessed Dec 42018.

7. Statistics Bureau, Ministry of Internal Affairs and Communications. Table 11. https://www.e-stat.go.jp/stat-searc h/file-download?statInfId=000031569575\&fileKind $=1$. Accessed Dec 42018.

8. Tomita S, Mitoku K: Health behaviors of middle-aged public assistance recipients: Problems and challenges. Kawasaki Med Wel J 2011; 21: 145-150.

9. Saito J, Kondo N, Takagi D: Factors related to consultation of health evaluation in welfare recipients. J Health Welf Stat 2018; 65: 15-20.

(Received, October 9, 2018)

(Accepted, June 14, 2019)

(J-STAGE Advance Publication, July 15, 2019) 